\title{
Organizational Reasons For Decision Aid Implementation
}

Jennifer L. Blaskovich, (E-mail: jenblask@yahoo.com), University of Nebraska, Omaha Brian P. McAllister, (E-mail: bmcallis@uccs.edu), University of Colorado, Colorado Springs

\begin{abstract}
Although substantial research efforts have been devoted to determining the reasons for the success and failure of decision aids in organizations, little has been done to examine the reasons why an organization chooses to implement the technology. We propose that understanding the relationship between decision aids and organizational reasons for implementation can assist in achieving a higher level of congruence between the organizations' goals and the technology. This paper proposes and empirically tests a framework that categorizes four primary reasons - improved decision-making, improved financial outcomes, improved communication processes, and improved learning/training processes. The results support the four proposed dimensions and provide a structure to the multitude of potential reasons for developing and implementing decision aid technology. The framework can be used by organizational managers in the initial stages of implementing a decision aid technology as well as during the functional stages of the decision aid to assess the initial and ongoing contribution the decision aid is making toward meeting organizational goals.
\end{abstract}

\section{INTRODUCTION}

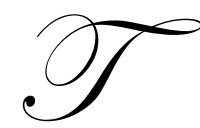

he combination of a fiercely competitive global market, an evolving regulatory environment and rapid technological development have made decision aids an indispensable tool for financial professionals in all types of organizations. Technology that aids decision makers in collecting and analyzing financial data is essential to the success of virtually all enterprises today (Khanna 2004). In fact, financial applications historically represent the most frequent uses of expert system technology, a specific type of decision aid technology (Brown and Phillips 1995).

Although there are many potential benefits of decision technology in financial settings, development and implementation comes with a hefty price tag. Organizations invest substantial resources in decision technology, so failure of the technology to meet expectations can be costly. As a result, significant effort within academic research has been devoted to the investigation of decision aid success and failure (Silver 1990; Whitecotton 1996; Brown and Jones 1998; Arnold et al. 2004). However, the findings of this body of work have not been complete because research has been less diligent in the exploration of the relationship between decision aid technologies and organizational factors. In particular, Bouwman (1996) states that the factors examined in most decision aid research simply identify the symptoms of success or failure and that much more investigation is needed to generate a more complete understanding of decision aid technology. While previous research has proposed a number of potential benefits of decision aid technologies, the potential reasons for why an organization implements a decision aid have not been formally identified or tested.

Our paper explicitly examines why an organization chooses to introduce financial-based decision aids by introducing the construct: "Reasons for Decision Aid Implementation." Organizations implement financial-based decision aids for many specific purposes. For example, financial institutions use decision aid technologies to manage investment and loan portfolios and hospitals use these technologies to manage insurance contracts and control healthcare costs. While these reasons for decision aid implementation are valid in terms of specific purposes and outcomes, we contend that organizations should consider classifying the reasons associated with implementing a decision aid 
technology into a structured framework. This classification framework may be particularly useful in assessing the "fit" or congruence between why an organization initially implements decision aid technologies and both the expected and actual benefits received from the decision aid technologies. The higher the level of congruence, the more successful a decision aid is likely to be for an organization.

We propose that organizations have four primary reasons for implementing decision aids: improved decisionmaking, improved financial outcomes, improved communication processes, and improved learning/training processes. We have formally tested this proposition using a survey methodology. Specifically, a questionnaire was developed and empirically tested using confirmatory factor analysis (CFA) to measure the four dimensions of the Reasons for Decision Aid Implementation construct. The results from the CFA support our proposition that this construct consists of the four pre-defined dimensions and provides a structure to the multitude of potential reasons for developing and implementing decision aid technology.

The paper proceeds as follows. The next section combines the individual and organizational levels of analysis by introducing the construct: Reasons for Decision Aid Implementation. We argue that this construct consists of four dimensions, and draw on prior research in decision aids to formalize this proposition. The third section describes the survey methodology we utilize for testing the relationships proposed in this paper. The fourth section analyzes the results and the final section summarizes the study and provides limitations and avenues for future research.

\section{REASONS FOR DECISION AID IMPLEMENTATION}

Guitouni (2005) notes that decision aids should be developed to improve organizational performance, but that the rational relationships between organizational objectives and decision aids have not been well-established or defined. At best, previous research has identified potential benefits of decision aids, but has not formalized the reasons why decision aids are created or purchased by organizations. Fried (1987) and Liang (1988) report the results of a survey commissioned by SRI International in 1987 that asked U.S. corporations to identify the leading benefits of knowledge-based applications. The result of the SRI survey and other decision aid research is a list of purported benefits, ranging from the specific 'faster communication of rules changes' to the general 'knowledge sharing'. In an attempt to provide structure to the multitude of potential benefits, we have summarized the list into four key categories as follows: 1) decision making processes, 2) improved financial outcomes, 3) communication processes, and 4) learning/training processes.

Specific benefits in the first category, decision-making processes, include more consistent decision-making between individuals in an organization and across divisions or sub-units within an organization as well as improved service and support provided to internal users. Audit firms cite consistency of decision-making across engagements and over time as a primary benefit of decision aids (Bedard and Graham 2002; Brown and Murphy 1990). Ashton and Willingham (1988) believe that aided decisions will be more consistent over time and across individuals than unaided decisions. Consistency is improved by providing structure to the decision process. Prior research found that unaided decision-makers consistently identified important inputs to a decision, but inconsistently combined those inputs to reach a judgment (Einhorn 1972). Decision aids can structure information input and the combination of input cues in order to reach more consistent decisions. This structure can increase the consistency of a single decision-maker over time or of multiple decision-makers across an organization.

Also included in the first category of benefits are improvements in the level of service provided to internal users of the decision aid. Arnold et al. (2004) propose that a decision aid has the potential to serve users by acting as an "electronic colleague" (p.23) throughout the decision-making process. Decision aids can augment professional judgment by providing a decision maker with a "second" opinion for comparative purposes and supporting "what if" analyses (Elliott and Kielich 1985; Abdolmohammadi and Usoff 2001). Additionally, aids can improve decisions by forcing a user to consider all relevant information, to appropriately weight the importance of the information, and ease the cognitive strain that can result in mental fatigue and errors (Messier 1995). 
Decision aid benefits in the second category address financial outcomes. Competitive pressures have motivated many organizations to operate more efficiently, and decision aids can help organizations achieve this goal in a number of ways. Decision making time is reduced by focusing users' thoughts on relevant issues and providing quick and error-free computations. Valuable expert time is freed to focus on complex, high-level judgments. As a result, operational costs are reduced and profitability ultimately improves. Additionally, the level of staffing required by the organization can be decreased. Although Arnold et al. (2004) argue against replacing experts with aided nonexperts for highly complex decisions, the use of a decision aid to automate low-level tasks allows an organization to streamline its workforce. Using a decision aid to perform these tasks reduces total staffing levels and allows the organization to redistribute scarce resources more effectively and efficiently.

The third category of benefits pertains to improvements in organizational communication. Decision aids capture expert knowledge and disseminate that information to non-experts in the organization. Management of an organization can use aids to quickly communicate new information to non-experts and changes in company policies and procedures to the entire workforce. Timely notification of new or revised information can improve efficiency, avoid costly delays in implementation of plans, and reduce exposure to litigation.

Improvements in employee learning and training processes comprise the fourth category of benefits. Decision aids can fuel knowledge development through formal training programs and informal, on-the-job guidance. Expensive and time-consuming one-on-one training can be replaced by decision aids that use real world simulations to teach inexperienced professionals (Abdolmohammadi and Usoff 2001; Messier 1995; Elliott and Kielich 1985). Aids may make the expertise of a firm's top technical managers available to less experienced personnel and teach them what information is important and how information is used in reaching a decision (Elliott and Kielich 1985). Novices can learn from an expert's "reasoning" that has been built into the decision aid. This is particularly beneficial when the aid provides users with an explanation of the aid's recommendation. Finally, because decision aids allow captured expertise to be distributed and shared, experts can augment their own knowledge with that of other experts across the organization (Abdolmohammadi and Usoff 2001).

\section{METHODOLOGY}

A questionnaire was mailed to the sample of large hospitals. Hospitals were specifically chosen since decision aid technologies are commonly used for estimating the impact of proposed managed care contracts and for budgeting decisions. Also, several "off-the-shelf" software packages using decision aid technologies and specific to hospitals are available.

The questionnaire consisted of an initial list of items based on the four factors expected to measure the Organizational Reasons for Decision Aid Implementation construct. A review process was undertaken to refine, delete, and validate the initial list of items. The final questionnaire contained a total of twelve items for decision making processes (3 items), improved financial outcomes (3 items), communication processes (3 items), and learning/training processes (3 items). A forced response, five point Likert scale with poles from strongly disagree to strongly agree and with several reverse-scored responses was used in the final questionnaire. The questionnaire also included an open-ended question requesting the name of the decision aid technology used in the hospital and two forced response questions asking the total number of employees and total assets of the hospital. Each questionnaire was sent to the attention of each hospital's chief information officer (CIO). The CIO names and hospital addresses were obtained from public sources. The hospitals receiving questionnaires were guaranteed anonymity for all responses by agreeing to allow aggregate results to be published without reference to specific hospitals.

The questionnaire was mailed in March 2005 to 295 hospitals. Respondents were allowed to respond to the questionnaire by completing and returning a paper copy of the questionnaire or completing an on-line version of the questionnaire. The on-line option was provided to facilitate the process of completing the questionnaire for respondents in order to improve the questionnaire response rate. Over $46 \%$ of the respondents used the on-line option for completing the questionnaire. 


\section{RESULTS}

\section{Respondents}

In total, 45 usable questionnaires were returned, corresponding to a $15 \%$ response rate. The responding hospitals were very large in size as measured using number of employees $(97.8 \%$ of hospitals had more than 1,000 employees and $22.2 \%$ had more than 10,000 employees) and total assets (55.6\% of hospitals had at least $\$ 500$ million in total assets). In addition, $93.3 \%$ of responding hospitals purchased their decision aid technologies rather than creating the technologies in-house.

\section{Confirmatory Factor Analysis}

A confirmatory factor analysis (CFA) was performed to determine the validity of the four-factor measurement model hypothesized for the Reasons for Decision Aid Implementation construct. Table 1, panel A provides a summary of the model fit statistics for the measurement model. Hu and Bentler (1998) recommend a twoindex strategy for determining model fit by reporting standardized-mean square residual (SRMR) and supplementing with another index. As a supplemental index, the incremental fit index (IFI) is chosen since this particular index is not sensitive to sample size (Hu and Bentler 1998).

Table 1

Results from Confirmatory Factor Analysis

Panel A: Fit Indices

\begin{tabular}{|l|c|}
\hline Fit Index Type & Fit Index \\
\hline & \\
\hline Standardized-mean square residual & 0.067 \\
(SRMR) & 0.945 \\
\hline Incremental fit index (IFI) & \\
\hline
\end{tabular}

Panel B: Standardized Factor Loadings and Cronbach's Alpha

\begin{tabular}{|c|c|c|}
\hline Factor & Cronbach's Alpha & Factor Loadings $^{2}$ \\
\hline 1. Improved Decision Making Processes & 0.715 & \\
\hline a. More consistent decision making across divisions & & 0.798 \\
\hline b. More consistent decision making over time by non-experts & & 0.774 \\
\hline c. Improves the level of service provided to internal users & & 0.465 \\
\hline 2. Improved Financial Outcomes & 0.612 & \\
\hline a. Reduces operational costs & & 0.695 \\
\hline b. Improves profitability & & 0.556 \\
\hline c. Decreases the level of staffing required & & 0.545 \\
\hline 3. Improved Communication Processes & 0.662 & \\
\hline a. Provides new information to non-experts & & 0.755 \\
\hline $\begin{array}{l}\text { b. Improves communication by providing standardized language } \\
\text { for users of the system }\end{array}$ & & 0.601 \\
\hline $\begin{array}{l}\text { c. Improves communication by providing faster notification of } \\
\text { changes in company policies }\end{array}$ & & 0.566 \\
\hline 4. Improved Learning/Training Processes & 0.781 & \\
\hline a. Improves decision making by non-experts & & 0.949 \\
\hline b. Provides availability of expertise to less experienced staff & & 0.707 \\
\hline c. Improves the training of non-experts & & 0.537 \\
\hline
\end{tabular}

All factors are significant at $P=0.05$ 
A SRMR value less than 0.08 and an IFI close to 0.95 is desirable and indicates good model fit between the hypothesized model and the observed data (Hu and Bentler 1998). For the measurement model in this study, the SRMR is 0.067 and the IFI is 0.945 . Both of these indices indicate good model fit for the measurement model tested and provide evidence that a four factor structure is valid for the Reasons for Decision Aid Implementation construct.

Table 1, panel B shows the factor loadings and Cronbach's Alpha statistics for the measurement model. All factor loadings are statistically significant at $\mathrm{p}<0.05$ demonstrating the items measured have convergent validity. In addition, Cronbach's Alpha for each of the four factors is greater than 0.60 , providing evidence that the individual items within each factor are being measured in a reliable and consistent manner. Alpha levels slightly below the traditional rule of thumb 0.70 are generally acceptable when the scale length is less than approximately 14 items and the data represent early stage social science research, as is true in the current study (Streiner 2003; Cortina 1998; Nunnally 1967).

\section{CONCLUSION}

Because of their potential for improving the organizational effectiveness and efficiency, financial-based decision aid technologies are now commonplace in organizations worldwide. Although the potential benefits of decision technology are many, development and implementation comes with a hefty price tag. The construct developed in this paper, "Reasons for Decision Aid Implementation," provides a framework to effectively match and measure the initial reasons an organization introduces decision aid technologies along with the potential benefits of the technology. The framework can be used by organizational managers in the initial stages of implementing a decision aid technology as well as during the functional stages of the decision aid to assess the initial and ongoing contribution the decision aid is making toward meeting organizational goals. Since this research study is exploratory in nature, the validity of the research findings are limited by the sample size of respondents to our questionnaire. In addition, the survey responses are from only one industry. Future research should attempt to refine and validate the research instrument through larger sample sizes and by expanding the research to other industries.

In conclusion, Messier (1995) notes that research has generally assumed that some level of management approved the introduction of a decision aid. However, research has not formally analyzed the reasons management approves the introduction of the decision aid in an organization in the first place. This paper summarizes the reasons for decision aid implementation into a structure that organizations can potentially use to measure these benefits and ultimately the success or failure of the decision aid technology.

\section{REFERENCES}

1. Abdolmohammadi, M.J. and C.A. Usoff. 2001. The Assessment of Task Structure, Knowledge Base, and Decision Aids for a Comprehensive Inventory of Audit Tasks. Quorum Books. Westport, CT. 43-63.

2. Abernathy, M.A. and P. Brownell. 1997. Management Control Systems in Research and Development Organizations: The Role of Accounting, Behavior and Personnel Controls. Accounting, Organizations and Society. (Volume 22, Numbers 3/4): 233-248.

3. Anthony, R.N. 1965. Planning and Control Systems: A Framework for Analysis. Harvard University Press. Cambridge, MA.

4. Arnold, V., P.A. Collier, S.A. Leech, and S.G. Sutton. 2004. Impact of Intelligent Decision Aids on Expert and Novice Decision-Makers’ Judgments. Accounting and Finance (Volume 44): 1-26.

5. Ashton, R.H. 1990. Pressure and Performance in Accounting Decision Settings: Paradoxical Effects of Incentives, Feedback, and Justification. Journal of Accounting Research. (Supplement): 148-186.

6. Ashton, R.H. and J.J. Willingham. 1988. Using and Evaluating Audit Decision Aids. In Audit Symposium IX: Proceedings of the 1988 Touch Ross/University of Kansas Symposium on Auditing Procedures, edited by Srivastava, R.P. and J.E. Rebele. University of Kansas. 1-25.

7. Bedard, J.C. and L.E. Graham. 2002. The Effects of Decision Aid Orientation on Risk Factor Identification and Audit Test Planning. Auditing: A Journal of Practice \& Theory. (Volume 21, Number 2): 39-56.

8. Bell, T.B., J.C. Bedard, K.M. Johnstone, and E.F. Smith. 2002. KriskSM: A Computerized Decision Aid for Client Acceptance and Continuance Risk Assessments. Auditing: A Journal of Practice and Theory. (September).

9. Brown, C.E. and M.E. Phillips. 1995. Expert Systems for Management Accounting Tasks. The IMA Foundation for Applied Research, Inc. Montvale, NJ. 
10. Brown, D.L. and D.R. Jones. 1998. Factors that Influence Reliance on Decision Aids: a Model and an Experiment. Journal of Information Systems. (Volume 12, Number 2): 75-94.

11. Bouwman, M.J. 1996. Opportunities for behavioral research in AIS: the matter of expertise. Advances in Accounting Information Systems (Volume 4): 255-278.

12. Cortina. J.M. 1993. What is coefficient alpha? An examination of theory and applications. Journal of Applied Psychology. (Volume 78): 98-104.

13. Dewett, T. and G.R. Jones. 2001. The Role of Information Technology in the Organization: A Review, Model and Assessment. Journal of Management. (Volume 27): 313-346.

14. Einhorn, H.J. 1972. Expert Measurement and Mechanical Combination. Organizational Behavior and Human Performance. 7, 86-106.

15. Elliott, R.K. and J.A. Kielich. 1985. Expert Systems for Accountants. Journal of Accountancy. (September): $126-134$.

16. $\quad$ Fried, L. 1987. The Dangers of Dabbling in Expert Systems. Computerworld. (June 29): 65-72.

17. Glover, S.M., D.F. Prawitt, and B.C. Spilker. 1997. The Influence of Decision Aids on User Behavior: Implications for Knowledge Acquisition and Inappropriate Reliance. Organizational Behavior and Human Decision Processes. (Volume 72, Number 2): 232-255.

18. Guitouni, Adel. 2005. Decision-aid to improve organizational performance. European Journal of Operational Research (162): 581-583.

19. Huber, G.P. 1990. A Theory of the Effects of Advanced Information Technologies on Organizational Design, Intelligence, and Decision Making. Academy of Management Review. (Volume 15, Number 1): 47-71.

20. Kaplan, S.E., J.H. Reneau, and S.M. Whitecotton. 2001. The Effects of Predictive Ability Information, Locus of Control, and Decision Maker Involvement on Decision Aid Reliance. Journal of Behavioral Decision Making. (Volume 14): 35-50.

21. Khanna, Pooman. 2004. CFOs lack key technology to aid with decision-making. Computing Canada (Volume 30, Issue 16): 1-4.

22. Kleinmuntz, B. 1990. Why We Still Use Our Heads Instead of Formulas: Toward an Integrative Approach. Psychological Bulletin. (Volume 107, Number 3): 296-310.

23. Laudon, K.C. and J.P. Laudon. 2001. Management Information Systems: Organization and Technology in the Networked Enterprise. (Fourth Edition). Prentice Hall, Inc. Upper Saddle River, NJ.

24. Liang, T. 1988. Expert Systems as Decision Aids: Issues and Strategies. Journal of Information Systems. (Spring): 75-94.

25. Luft. J. and M.D. Shields. 2000. Mapping Management Accounting: Making Structural Models from Theory-Based Empirical Research. Working Paper.

26. Mauldin, E.G. 2002. The Effects of Information Technology on Incentive Contracting. Working Paper.

27. Mauldin, E.G. and L.V. Ruchala. 1999. Towards a Meta-Theory of Accounting Information Systems. Accounting, Organizations and Society. (Volume 24): 317-331.

28. Mauldin, E.G. and L.V. Ruchala. 2002. The Effects of Task Complexity and Performance-Based Bonus Incentives on Decision Aid Reliance. Working Paper

29. Messier, W.F. Jr. 1995. Research in and Development of Audit Decision Aids. In Judgment and Decision Research in Accounting and Auditing, edited by Ashton, R.H. and A.H. Ashton. Cambridge University Press. New York. 207-228.

30. Nunnally, J.C. 1967. Psychometric Theory. New York: McGraw-Hill.

31. Payne, J.W., J.R. Bettman, and E.J. Johnson. 1993. The Adaptive Decision Maker. Cambridge University Press. New York. 20-69.

32. Perrow, C. 1970. Organizational Analysis: A Sociological View. Wadsworth Publishing Company. Belmont, CA.

33. Rohrmann, B. 1986. Evaluating the Usefulness of Decision Aids: A Methodological Perspective. In New Directions in Research on Decision Making, edited by Brehmer, B., H. Jungermann, P. Lourens, and G. Sevon. Elsevier Science Publishers. North-Holland. 363-381.

34. Shanteau, J. 1992. Competence in Experts: The Role of Task Characteristics. Organizational Behavior and Human Decision Processes. (Volume 53): 252-266.

35. Silver, M.S. 1990. Decision Support Systems: Directed and Nondirected Change. Information Systems Research. (Volume 1, Number 1): 47-70.

36. Simons, R. 1995. Levers of Control: How Managers Use Innovative Control Systems to Drive Strategic Renewal. Harvard Business School Press. Cambridge, MA.

37. Streiner, D. 2003. Starting at the beginning: An introduction to coefficient alpha and internal consistency. Journal of Personality Assessment (Volume 80, Issue 1): 99-103.

38. Whitecotton, S.M. 1996. The Effects of Experience and Confidence on Decision Aid Reliance: A Causal Model. Behavioral Research in Accounting. (Volume 8): 194-216.

39. Whitecotton, S.M. and S.A. Butler. 1998. Influencing Decision Aid Reliance Through Involvement in Information Choice. Behavioral Research in Accounting. (Volume 10): 182-206. 